\title{
La construcción cultural de la realidad social en la Modernidad
}

\section{Juan A. Roche Cárcel}

Universidad de Alicante. Departamento de Sociología I y Teoría de la Educación Ja.roche@ua.es

\section{Resumen}

En el presente artículo se analiza la evolución de la definición del concepto de realidad social en Occidente desde la Ilustración hasta la actualidad. La idea fundamental que quiere destacar es que la visión de la realidad que posee la sociedad contemporánea es el fruto de un largo proceso en el que la cultura - la filosofía, el arte, la ciencia-, con su poder estructurante y desestructurante, ha tenido un decisivo papel. Para ello y tras señalar la importancia que el tema de la realidad tiene para la sociología, dedico una serie de apartados a cada una de las cuatro etapas en las que he dividido la Modernidad: la Ilustración — que está pegada a la realidad, pero que comienza a cuestionarla_-, el Romanticismo —en el que la realidad ya no es un determinante de la sociedad-, la Modernidad — que ha convertido a la realidad en un paradigma tecnológico — y la Posmodernidad — que ha transformado a la realidad en una mercancía más que está en venta. Finalmente, concluyo indicando que el pensamiento, la estética y la ciencia, es decir, la cultura, ha entregado la realidad a un orden económico dominante.

Palabras clave: realidad social, sociología de la cultura, sociología del conocimiento.

\section{Abstract. The Cultural Construction of Social Reality in Modernity}

Along this article I'll try to analyze the evolution of the concept of «social reality» in Occidental world since Illustration to present time. The main topic is that the vision of reality that contemporary society shows is the result of a long process in which culture -i.e. philosophy, art, science- due to its structuring and unstructuring power, has developed a decisive role. To get this objective and after pointing out the importance of the theme of reality to sociology, I've dedicated a different par to each of the four stages in which I've divided modernity: Illustration — closed to reality but when it is first discussed-, Romanticism — society is not any more determinate by reality—, Modernity — reality has been turned into a technological paradigm - , and Post-modernity — reality has been transformed into merchandise for sale. My conclusion is that thought, aesthetic and science, in other words, culture, has given over reality to a dominant economical order.

Key words: social reality, sociology of culture, sociology of knowledgement. 


\section{Sumario}

\section{Introducción}

2. La Ilustración está pegada a la realidad, pero comienza a cuestionarla

3. En el romanticismo la realidad ya no es determinante en la actuación humana

4. La Modernidad o la sustitución de la realidad por un paradigma tecnológico
5. La Posmodernidad o la venta de la realidad

6. Conclusiones: el doble rostro científico-tecnológico y hedonista-consumista de la Posmodernidad

Bibliografía

\section{Introducción}

\subsection{La sociología y la realidad. Bases teóricas y metodológicas}

Se puede considerar la expresión «realidad», en su carácter evolutivo, desde varios puntos de vista y desde diversos campos culturales como la filosofía, la ciencia o el arte. La filosofía, por ejemplo, ha visto el problema de la realidad - lo que es la realidad- como un asunto metafísico, de esencia o de existencia (Ferrater 1986: 2790 y s.). La ciencia, por su parte, llama real a «lo que existe en algún lugar del continuo espacio temporal de cuatro dimensiones» (Bunge 1985: 76), mientras que el arte relaciona la realidad con la mimesis - o imitatio - , sea ésta o bien una reproducción del mundo exterior o una copia de la apariencia de las cosas - los dos significados antiguos, el de la Grecia del siglo V aC y el de Sócrates, Platón y Aristóteles-o bien el análisis y no la imitación de la realidad — el significado que se adopta en el realismo decimonónico literario y artístico- (Tatarkiewicz 1992: 301 ss.). Se puede indicar, por tanto, que la realidad es un concepto fundamentalmente cultural definido desde la filosofía, el arte y la ciencia a lo largo de la historia occidental.

La sociología ha heredado de la cultura, sobretodo de la filosofía, el interés por la realidad. De ahí que, en este tema, ambas disciplinas mantengan una proximidad que se refuerza por el hecho de que la sociología, en este asunto, se encuentra a mitad de camino entre el filósofo y el hombre de la calle y porque el conocimiento de la misma conlleva implicaciones filosóficas, en tanto que tal conocimiento ha sido tradicionalmente un problema central de la filosofía. Además, las dos se mueven en un ámbito de generalidad y ambas cuestionan reflexivamente sus supuestos (Beltrán 2003: 216), por lo que no debe extrañarnos que la sociología tenga que dialogar permanentemente con aquélla si no quiere perder su propio objeto de investigación. Un objeto que tiene mucho que ver con la realidad porque, como señala Max Weber en Sobre la teoría de las ciencias sociales (1974: 11 y 36), la ciencia social es una ciencia de la realidad, una ciencia que "aspira al orden racional de la realidad empírica». Lo mismo indica Miguel Beltrán, en La Realidad Social (2003: 95), donde considera a la sociología como la ciencia que estudia la realidad social. 
Se evidencia, además, la importancia que esta cuestión de la realidad ha revestido para la sociología por la dedicación a este tema de algunos de los sociólogos más destacados, como por ejemplo Karl Marx (Beltrán 2003: 30 y s.), Max Weber (1974: 11; 1990: 79 y s.), Émile Durkheim (1985: 47 y s.), (Ritzer 2001a: 227-8), Georg Simmel (1986: 173 y s.), Max Sheller (Berger et al. 2001: 21-3), W.I. Thomas (Ritzer 2001b: 65), Robert Merton (Berger et al. 2001: 26), Pierre Bourdieu (1982: 14 y s.), Alfred Schütz (1993: 169 y s.), Ritzer (2001a: 500-1), Peter Berger y Thomas Luckmann (Berger et al. 2001), Oltra et al. (2004: 771), Erving Goffman (1981), Niklas Luhmann (2000), Guy Debord (2003) y, en el ámbito español, Miguel Beltrán (2003) o Celso Sánchez Capdequí (2004).

A pesar de que la sociología carezca de un método propio o privilegiado con el que emprender en exclusiva la investigación y el análisis de la realidad social (Beltrán 2003: 110), en mi opinión ha abordado esta temática desde tres grandes perspectivas. La primera, ha debatido si la realidad es mental — posición que defienden, por ejemplo, el filósofo John R. Searle, en La construcción de la realidad social (Searle 1997: 20 y s.; Oltra et al. 2004: 774), y Karl Mannheim, a través del concepto de ideología, que intenta comprender que no existe pensamiento humano que no esté influido ideológicamente por su contexto social (Mannheim 1966: 232; Berger et al. 2001: 24) — o fenomenológica — con Alfred Shütz y Berger y Luckmann como representantes más sobresalientes. La segunda, íntimamente relacionada con la anterior, se ha centrado en dilucidar si la realidad la hacen los intelectuales - Mannheim es posiblemente, en este respecto, el sociólogo más importante- o si se construye en la vida cotidiana, esto es, que la realidad por excelencia es la vida cotidiana (Berger et al. 2001: 39) — despuntan Shütz, Berger, Luckmann y Erving Goffmann. Finalmente, ha habido una interesante discusión entre nominalistas - los que defienden que la realidad es sobretodo de carácter individual, resaltando en este sentido Max Weber y Max Sheller - y realistas - los que sostienen que la realidad es la sociedad, E. Durkheim a la cabeza. ${ }^{1}$

Con respecto a estas perspectivas, quiero dejar claro ante todo que mi aportación no es fenomenológica aunque utilice algunos de sus aspectos, pues comparto el modo en el que la sociología del conocimiento ha entendido tradicionalmente el tema de la realidad social, es decir, como una historia intelectual, como una historia de las ideas (Mannheim 1990: 18-21). Pero este artículo bascula dialécticamente entre el mundo de los intelectuales y el de la vida cotidiana y entre el realismo y el nominalismo, y de ahí que utilice la hermeneútica como un instrumento que permita la interpretación de los discursos para la comprensión de su sentido invocando el marco social en el que se generan y la posición social de los interlocutores. Finalmente, también quisiera destacar que soy deudor de la sociología del conocimiento e igualmente

1. Este debate entre nominalistas y realistas (Beltrán 2003: 60 y s.) se corresponde con la discusión acerca de si la sociedad es objetiva o subjetiva, es decir, si posee facticidad objetiva o significado subjetivo (Berger et al. 2001:35). 
de la sociología de la cultura. Por tanto, mi trabajo se engloba dentro de ambas subdisciplinas sociológicas, utiliza una metodología hermeneútica e histórica y parte de una visión de la cultura entendida como estructura y proceso.

\subsection{Objetivos}

En coherencia con estas bases teóricas y metodológicas, voy a intentar aquí examinar la idea de realidad y su evolución en la sociedad moderna buscando los siguientes objetivos básicos:

1. Teniendo muy presente que las ideas se hallan tanto en la mente de los actores como en las prácticas sociales mismas (Beltrán 2003: 200), desarrollaré una historia de las ideas sobre la realidad social con el fin de observar particularmente cuál ha sido su curso en la Modernidad - especialmente desde la Ilustración-, esto es, cómo ha llegado a ser, cómo es en la actualidad y por qué ha llegado a serlo (Beltrán 2003: 113 y s.).

$2 .^{\circ}$ Interpretaré de qué manera la realidad social construye los discursos y cómo éstos erigen aquélla, siendo consciente de que construir la realidad es también definirla (Beltrán 2003: 50 y s.) y de que en esa conceptualización tiene un decisivo papel el mundo de la cultura (Berger et al. 2001: 59).

3. ${ }^{\circ}$ Pero como no considero que la cultura sea una superestructura, sino que forma parte estructural de la vida cotidiana, de la vida social y como entiendo, además, que también es proceso, cambio, devenir, innovación y desestructuración (Tortosa 1981: 12-3), analizaré de qué manera la cultura estructura y desestructura la idea de la realidad social.

$4 .^{\circ}$ Finalmente, a través de la interdisciplinariedad, examinaré distintos campos culturales (Mannheim 1962: 97 y s.; Barboza 2002; Barboza [en prensa]) - la economía, la filosofía, la ciencia, el arte... - , con el fin de hallar entre ellos equivalencias u homologías estructurales que me permitan encontrar la concepción general que articula la vida social.

\subsection{La subjetividad y el cuestionamiento de la realidad}

Como se va a poder comprobar, el concepto de realidad sufre en el mundo moderno un embate que va a ir paulatinamente deteriorando los tradicionales sentidos filosófico, científico y artístico a los que me he referido anteriormente, en la medida en que muere la metafísica — como señala Heidegger-, desaparece el concepto de mimesis del ámbito artístico y se rompe el continuo espacio-temporal al que tradicionalmente se vinculaba la ciencia. Y todo ello desembocará en una progresiva huida de la realidad y en la sustitución de ésta por otras realidades más subjetivas y evanescentes. Ello ha sido posible, fundamentalmente, por el característicamente occidental crecimiento de la individualidad, de la subjetividad, especialmente en la Modernidad (Habermas 1989: 28; Burkhard 1962: 123 y s.; Bloom 1995: 37 y s.). Nuestra civilización parece marcada, desde Platón y Aristóteles y desde el Nuevo Testamento y el 
origen del cristianismo, por una dialéctica que enfrenta al sujeto con el objeto, a la idea con el mundo, a la materia con el espíritu y a la realidad con la irrealidad. Pero es en la Modernidad cuando esta tensión omnipresente se bascula finalmente hacia uno de los dos polos en detrimento del otro (Roche [en prensa]), puesto que tras la crisis de la concepción religiosa del hombre (Tollinchi 1989, II: 846), este individuo moderno siente que se desintegra y que debe cuestionar su identidad y su unidad, algo de lo que se percató muy bien Descartes. A partir de él, toda la historia de la filosofía occidental parece empeñada en querer deducir verdades objetivas basadas en la convicción de que el sujeto existe, puesto que el subjetivismo - el descubrimiento de uno mismo como base del edificio del conocimiento-, el sujeto autoconsciente que piensa acerca de su pensamiento, está tan ensimismado en sí mismo que se olvida o se distancia del objeto y se vuelve incapaz de entender cualquier otra realidad que no sea la mental. Así, para Descartes, el pensar y el ser, la verdad y la realidad se sitúan juntos en el intelecto (Cassirer 1950: 114-5), lo que significa que la conciencia evidencia el poder del sujeto y el fracaso del objeto. Si a esto le añadimos la máxima cartesiana, "cogito ergo sum: pienso luego existo", que convierte a la duda en la clave de la única certeza posible y la separación que este mismo filósofo efectúa entre res cogitans y res extensa, entre pensamiento y realidad exterior y entre mente y cuerpo, no nos extrañe que el pensamiento occidental posterior se dirija hacia «la muerte de la convicción» (Fernández-Armesto 1999: 173 y s.) y, con ella, hacia el cuestionamiento de la realidad misma. En efecto, con Descartes ha quedado desbrozado el camino para que la cultura y la sociedad modernas, empujadas por el subjetivismo, avancen progresivamente hacia una mayor separación entre el hombre y el mundo y entre la sociedad y el propio individuo, hacia una mayor abstracción, hacia la disolución de las certezas y hacia un mayor alejamiento de la realidad. Sin embargo, será en la Ilustración y en el Romanticismo cuando se establezcan los cimientos más sólidos para el desarrollo de este distanciamiento, que culminará en la sociedad contemporánea moderna y posmoderna.

\section{La Ilustración está pegada a la realidad, pero comienza a cuestionarla}

\subsection{Una sociedad de órdenes frente a una sociedad de clases}

La Ilustración se desarrolla aproximadamente desde 1721 hasta 1794 (Munck 2001: 8), por lo que abarca prácticamente todo el siglo XVIII. En esta centuria, se contraponen dos modelos sociales complementarios y contradictorios, esto es, una «sociedad de órdenes» jerarquizada y desigual en la que el grupo, el principio del nacimiento y el estatus adscriptivo prevalece sobre el individuo y una «sociedad de clases» en proceso de vertebración y de consolidación en la que luchaban por abrirse camino la movilidad social basada en el mérito personal y la primacía del individuo sobre el grupo de origen. En definitiva, es una sociedad dual aristocrática y burguesa en la que siempre se va a mantener en tensión la libertad, es decir, la articulación de la libertad individual con la 
solidaridad entre los miembros de una comunidad política (Iglesias 1999: 13 y 156) y la idea de realidad con la de irrealidad.

En efecto, como los nuevos filósofos defendieron que toda certeza debe apoyarse en un examen racional de nuestro conocimiento empírico, libre de toda creencia religiosa, de ataduras y de prejuicios, terminaron por destruir la fe humana en la tradición y en las creencias y, en su lugar, situaron la mente del sujeto humano (Pagden 2001: 31-2), continuando así los planteamientos cartesianos. Ello explica que, aunque fueron muy conscientes del constante cambio en la realidad exterior producido fundamentalmente por la revolución industrial y por el progreso científico y tecnológico, no sintieran necesidad — como sí lo hará el Romanticismo - de reclamar fuerzas estables y eternas que compensaran ese dinamismo (Mosse 1997a: 18-9). E igualmente revela la contradicción de que, si bien el apego a la realidad es dominante en el movimiento ilustrado - como se puede observar en Locke, en la historia, en la literatura o en la política (Mornet 1988: 88 y s.) —, la propia naturaleza filosófica de aquél y los acontecimientos políticos y sociales empujaron a las mentes más creativas y de más profundo calado a cuestionar paulatinamente esa adherencia a la realidad y a tratar de hallar un mundo diferente y alejado de la misma.

\subsection{La Ilustración es desgarradora, autocritica y disolvente de las certezas}

La Ilustración podría caracterizarse como desgarradora, autocrítica y disolvente de las certezas. Es desgarradora porque concibe un individualismo separador que produce una triple escisión del hombre con Dios, con su interior y con la sociedad. Esto le lleva a un nuevo concepto de la sociedad donde los seres humanos se unen a través de una extensa red de relaciones e interdependencias que adquieren la forma de contrato social (Flaquer 1995: 4-26). Pero es un contrato social que, tal y como fue formulado por Jean Jacques Rousseau (Iglesias 1999: 223 y s.), es artificial — cultural—y alejado, abstraído, de la naturaleza. Y es desgarradora porque la separación en esferas autónomas de la moral y de la religión, es decir, la laicización de la vida política y moral de los seres humanos, será lo que guíe el pensamiento ilustrado — como por ejemplo, en Montesquieu, que separa la moral de la política (Iglesias 1999: 152160) o en Kant, que divide la razón en teórica, moral y estética.

La Ilustración es autocrítica, pues en ella el sistema filosófico pierde su fuerza vinculativa y representativa y rompe constantemente sus rígidos límites, de manera que la filosofía se convierte en un proceso progresivo que transforma las estructuras fijas y acabadas en fuerzas activas (Cassirer 1950: 9 y s.). Fuerzas que están siempre en movimiento, que deben ser continuamente renovadas, que no permiten estructuras estables y que, por lo tanto, terminan siendo disgregadoras y fragmentadoras. El carácter autocrítico de la Ilustración se justifica, además, con Kant, quien defiende, en la Crítica de la razón pura (2003: 9), que "nuestra época es, de modo especial, la de la crítica» y con Foucault, que, en el «Seminario sobre el texto de Kant: Was ist Aufkhrung?» y en "Qué es la 
Ilustración", escribe que este movimiento supone una capacidad de interrogarse que conducirá inevitablemente a la autocrítica (Bello 1997: 20 y s.).

Finalmente, la Ilustración tiende a la disolución de las certezas por un conjunto de factores: su toma de conciencia de que la vida humana se ha convertido en una máscara, la evolución de la ciencia, las numerosas disputas y la marcha de los sucesos históricos. En el primer caso, el viejo tema moralista del ser y del parecer, del enfrentamiento entre la verdad y la mentira, es un tema recurrente en el siglo XVIII, si bien se van a dar dos paradigmas dominantes, el de Diderot y el de Rousseau (Iglesias 1999: 70 y 295 y s.). Por lo que se refiere a la ciencia, durante el siglo XVIII se irá relajando progresivamente el concepto fijo de forma aceptándose cada vez más la idea de evolución (Cassirer 1950: 51), además de imponerse una nueva concepción de la naturaleza que, desde Galileo, reduce sistemáticamente el mundo a su estructura matemática. Este método perdura en el siglo XVIII, pero comienza a ser cuestionado por Jean-Jacques Rousseau (2003: 185), por Voltaire (1988: 91) o por Montesquieu, quien denuncia la «sequedad de la geometría» en tanto que considera que la precisión que se le concede no se puede aplicar al mundo cambiante que es la realidad biológica y social humana, esto es, que la realidad no puede ser constreñida más que a costa de la reducción a símbolos matemáticos (Iglesias 1999: 392 y s.).

En cuanto a las múltiples controversias en las que se enzarzaron los pensadores, acabaron éstas por erosionar los valores culturales más importantes, por criticar a la realidad presente y por extender, al menos entre los filósofos, la duda (Munck 2001: 24 y s.) y el relativismo. Tal es el caso de Montesquieu, que comprende que no son posibles soluciones universales y definitivas para los asuntos humanos, ya que las sociedades presentan una gran variedad (Montesquieu 1997: 114 y 191), (Iglesias 1999: 113). E igualmente lo son Diderot (1983: 51), cuyo pensamiento es tan fluido y cambiante como la propia realidad (Cassirer 1950: 109), y D’Alembert, que transforma «la ilusión de certeza ofrecida por las ideas» claras y distintas de Descartes por las verdades probables (Pagden 2001: 52).

Finalmente, los sucesos contemporáneos más trascendentales, la Revolución Francesa y las conquistas napoleónicas, revelaron no sólo que el presente no resultaba todo lo racional, idílico y progresivo que cabría esperar, sino que la razón engendra también monstruos - Goya, Caprichos, El sueño de la razón produce monstruos (Vaughan 1995: 86). La trayectoria de la Revolución Francesa de 1789 tiene un impacto político y social enorme, ya que consigue derrotar al gobierno monárquico absolutista y a la sociedad tradicional aristocrática. Pero si, en estos aspectos, la revolución cumplimentaba los idearios ilustrados, en otro abría el camino al Romanticismo, pues para triunfar tuvo que coaligar la razón especulativa - las luces - con el oscuro impulso de las masas coléricas y, así, acabará presa de su propio pacto antinatural en el denominado período del «Terror», una etapa en la que la voluntad del pueblo y los principios ilustrados no sólo ya no acoplarán tan íntimamente sino que incluso llegarán a quebrantar su asociación. Como consecuencia del fracaso de esta alianza, la 
voluntad se transformará ahora en una voluntad de poder que rechazará hacer causa común con la claridad de la razón (Starobinski 1988: 39-40) y que demostrará la fragilidad de ésta y el poder de la pasión (Honour 1994: 19). La Revolución Francesa de 1789 supuso, pues, una conmoción considerable sobre muchos intelectuales europeos, al igual que las invasiones napoleónicas, que, dominadas por la guerra y por el deseo de conquista de Europa, rematarán lo que ya había anunciado la Revolución de 1789, es decir, la fulminación del entusiasmo inicial con el que se recibió la Ilustración y suscitarán en toda Europa el rechazo incluso de las mentes más racionales - Goya, Los fusilamientos del tres de Mayo. No extrañe que, como consecuencia de ambos acontecimientos políticos, la fe en la razón no fuera absoluta y que, poco a poco, se vayan abriendo camino ideas prerrománticas o románticas, constituyendo, por tanto, el Romanticismo un movimiento que, en gran parte, se explica como una respuesta a esos sucesos.

En definitiva, mientras se mantuvo la fe en la racionalidad, mientras los filósofos continuaron aspirando al progreso y a la perfección y mientras la persecución de la felicidad pareció un objetivo factible, Occidente fue feliz (Fernández-Armesto 1999: 173 y s.) y creyó en la realidad. No obstante, a finales del siglo XVIII — entre 1760 y 1770 — se vio que el progreso había fracasado, que la perfección había sido pospuesta, al menos en Europa, y que la dicha no era algo tan fácil de alcanzar. Entonces la duda se instaló en los ánimos, progresó el espíritu crítico y la incredulidad, se dislocó la fe religiosa y la fe monárquica, avanzó el escepticismo (Mornet 1988: 166-178) y la confianza en la realidad perdió su fuerza. La razón y la realidad fueron entonces encontradas superficiales, meras cosas exteriores al individuo (Mosse 1997a: 43).

\subsection{La importancia de la estética en la subjetivización de la realidad}

Este proceso puede apreciarse con una singular fuerza en la estética que es una de las partes del sujeto moderno (Bozal 1996b: 29), pues es uno de los elementos principales en el desarrollo de la conciencia humana - Charles Baudelaire (Jarque 1996b: 312). En la Ilustración todavía podemos encontrar en el pintor francés Jacques-Louis David, a través de su compromiso con la Revolución (Honour 1994: 225), una vinculación del arte de vanguardia con la política y, por tanto, una adscripción a los postulados neoclásicos que le conceden al arte un papel de imitación de la naturaleza. Pero algo evoluciona con Diderot, cuando - en el artículo redactado para la Enciclopedia-, a pesar de seguir adjudicándole un carácter imitativo al arte, destaca sus aspectos expresivos y cuando considera que lo que determina el efecto de la belleza es la «percepción de las relaciones» (Diderot 1994: 28; Arnaldo 1996b: 72). Este proceso de subjetivización del arte se consolida en el empirismo británico (Raquejo 1996: 245), que, aunque defiende una estética que investiga las cualidades físicas y psicológicas del objeto artístico (su belleza, su pintoresquismo y su sublimidad), termina considerando que el arte y la belleza se refieren al sujeto que las contempla o las produce y no al objeto (Pérez 1996: 30-45). La crisis de la 
imitación, ya abierta, se consolida en la segunda mitad del siglo XVIII, ya que paulatinamente será sustituida por los valores estructurales y psicológicos (perceptivos, emotivos, morales y anímicos). Por tanto, a partir de ahora, antes que imitativo el arte debe ser emotivo. Ello se evidencia con la teoría del gusto que reconoce que éste depende de las inclinaciones subjetivas y que le otorga un carácter relativo al convertirse la repercusión sobre los afectos individuales en el objetivo primordial del arte, lo que requiere abandonar los principios absolutos objetivos si se quiere explicar la validez universal de las manifestaciones estéticas (Arnaldo 1996b: 76-84). Pero será Kant quien —en la Crítica del juicio (2001: 117 y s.) — dé el paso decisivo en la subjetivización de las cuestiones estéticas y el que tenga una mayor trascendencia para el pensamiento estético romántico y contemporáneo. En esa obra, Kant defiende que no hay objeto exterior que el sujeto pueda conocer empíricamente, esto es, que todo conocimiento lo es desde el sujeto y en relación con él (Bozal 1996a: 182).

\section{En el romanticismo la realidad ya no es determinante en la actuación humana}

\subsection{Una época de transición: entre el feudalismo y la revolución burguesa}

Los orígenes del Romanticismo se hallan en el propio interior de la Ilustración (Mosse 1997a: 43), en pensadores como Rousseau, Diderot o Kant, en la estética neoclásica, también en el gran acontecimiento histórico del siglo XVIII, la Revolución Francesa de 1789, y en las invasiones napoleónicas, tal y como se ha visto. Esto explica que algunos pensadores hayan tratado de encontrar puentes de diálogo entre las ideas ilustradas y las románticas, unidas como están por el vértigo de los acontecimientos y de los rápidos cambios que se sucedían. Entre éstos se encuentran los filósofos Schiller (Jarque 1996d: 233-5), Lessing (Jarque 1996f: 93 y s.), Herder (Jarque 1996a: 87 y s.) y Hegel (Flaquer 1995: 4-5). Y los artistas Francisco de Goya (Honour 1994: 45-6; Starobinski 1988: 107 y s.; De Paz 1992: 383 y s.), Shelley, Schelling, Novalis (2004: 9-10) y Johann Heinrich Füssli (Starobinski 1988: 291), que no son en absoluto enemigos del pensamiento ilustrado, pues detestan la superstición, la injusticia y la intolerancia, si bien al mismo tiempo censuran su cerebral escepticismo, al que consideran superficial (Honour 1994: 291).

Todos ellos establecen unas sutiles y complejas relaciones entre el Romanticismo y la Ilustración que, en último extremo, son posibles porque la sociedad romántica es dual y consciente de hallarse en un mundo en transición. Y es que, aunque lo romántico — continuando y sistematizando la Ilustración - se convierte en otra forma distinta de denominar lo "moderno", esto es, lo opuesto a la antigüedad, el presente (Solana 1996: 292-3; Vaughan 1995: 10), también significa vivir entre un presente que no satisface y un pasado que ya no es útil, entre una tradición feudal en decadencia y el surgimiento de la reforma burguesa (De Paz 1992: 190). Y ello se sitúa históricamente entre fines del siglo XVIII, cuando se inició el Pre-romanticismo, y los años 
treinta y cuarenta del siglo XIX, en el momento en que el Romanticismo alcanza su apogeo y cuando poco a poco se va difuminando por el empuje de otras corrientes artísticas (Lorente 2002: 80).

Por lo demás, este movimiento constituye un talante que huye de cualquier definición o clasificación rigurosa (Mosse 1997a: 42), en tanto que su característica más innegable es la diversidad de lenguajes y de respuestas individuales que no producen una obra paradigmática y que continuamente se revisan por las transformaciones que afectan al mundo (Honour 1994: 15-9). No extrañe que August W. Schlegel se refiriera a las distintas tendencias románticas como impulsos que están activos y todavía en vías de completar su realización (Arnaldo 1996a: 202). Es preciso recordar, sin embargo, que estos procesos abiertos son el reflejo del dinamismo general que estaba afectando a la sociedad y a la cultura y, lo que es más importante, que esta vertiginosa marea de cambios fue percibida por los románticos, que enfatizaron el cambio y el desarrollo, lo que les empujó a considerar que la realidad ya no es determinante de la actuación humana (Mosse 1997a: 45). Pero si ello tiene lugar es debido a tres causas principales: la pasión por la subjetividad, la continuación de su trayectoria separadora y de disolución de las certezas y la huida de la realidad.

\subsection{La pasión por la subjetividad, la separación entre el hombre y el mundo y la huida de la realidad}

El individualismo romántico evoluciona, básicamente, a través de cuatro fases principales. La primera de ellas se caracteriza por la concepción protorromántica del yo - la autoconciencia- que impulsa la introspección, el descubrimiento y el culto a la originalidad y al genio. Pero este desvelamiento viene acompañado de la discordancia trágica entre el hombre-genio y el mundo y la sociedad, por lo que se sustituye la experiencia del mundo por la experiencia de sí al convertirse la introspección en un refugio frente a la realidad. En esta huida, se desvela el inconsciente, lo extraño - los sueños, la locura, la enfermedad, el suicidio, las raras criaturas, los demonios y la muerte-, es decir, lo que hasta aquí había estado oculto a la razón. Y es que se hizo un viaje hacia el interior humano no porque se rechazara la razón, sino porque se pretendía ampliarla hacia el sentimiento, en la medida en que se consideró que el sueño de la razón ya no produce monstruos sino pasiones (De Paz 1992: 31 y s.). La segunda fase está representada por la filosofía idealista alemana, la que conduce al sujeto a su máxima potencia, al pretender reducir el universo y la realidad entera al "yo pienso» y al comprimir la realidad, lo que equivale a ampliar el pensamiento (Tollinchi 1989, I: 900 y s.). La tercera fase, que se va gestionando poco a poco y que puede coincidir con las otras, se define por el traspaso del individualismo a la nación, como se puede apreciar en pensadores como Herder, Fichte, Schlegel o Novalis. Así, el Romanticismo político de los nacionalistas se hermana con el Romanticismo de la vida interior (De Paz 1992: 51). La cuarta fase, desarrollada a finales de siglo y que continúa en las primeras décadas del siglo XX, se caracteriza por convertir al sujeto en problemático, por 
preocuparse por la identidad y por la crisis del individualismo. Esta crisis acaba con la disolución del yo, de la personalidad y definiendo a un hombre sin atributos con el que se diluye también el carácter antropocéntrico de la sociedad (Tollinchi 1989, II: 900 y s.).

Esta descomposición del yo es paralela a la separación del hombre del mundo. Para el Romanticismo, que es — como lo había sido la Ilustraciónuna sociedad dual, el conflicto representa una forma esencial de la conciencia, es decir, que ningún aspecto escapa a los contrastes y a las luchas. Pero la novedad consiste en que todas las polarizaciones constituyen dos posibilidades que se pretende sean realizadas al mismo tiempo, lo que produce la sensación de trágica imposibilidad (De Paz 1992: 56). A esto hay que añadir que los románticos preferían lo potencial sobre lo acabado, pues para ellos no puede existir una estructura del mundo que nos aprisionaría, lo que les distingue hondamente de los ilustrados, para los que sí existía una estructura del mundo con fundamentos como la razón universal, el orden y la justicia. Es en torno a 1820 cuando se genera esta novedosa perspectiva en la que se va a defender que no hay una estructura de las cosas y que hay que intentar estallar esta estructura estable, es decir, romper la realidad en fragmentos (Berlin 1999: 37-193).

Junto a la separación del entorno, los románticos — sobre todo en Alemania - también desconectan la revolución burguesa de la sociedad de la que se nutre la cultura, es decir, ésta del capitalismo. Como se ha visto, esta disociación se forjó en el siglo XVIII, aunque el pensamiento dominante de esta centuria pretendía que la cultura progresase en armonía con la moderna sociedad capitalista (Jarque 1996c: 206-7). El Romanticismo lleva más lejos esta ruptura, en la medida en que propugna una huida de la realidad o la búsqueda de una situada más allá de una existencia humana cotidiana, determinada por los efectos de la revolución industrial. Una revolución que, paradójicamente, también se estaba distanciando de la realidad, pues desde el origen de la economía industrial y de mercado se desencadenó un aumento de la abstracción y una cierta fractura entre la vida económica y la social. Esto lo aprecia muy bien Karl Marx, ya que, para él, el trabajo humano, la producción económica, es el factor principal desencadenante de esa separación (Schmidt 1968: 17 y s.). El conjunto del Romanticismo, al menos intuitivamente, fue consciente de este poder separador de la economía capitalista, lo que explica que se situara en frente de la misma y de la clase social que la impulsó y que constituyera un revulsivo de las limitaciones de la mentalidad burguesa. Igualmente es consciente de la separación en esferas diferentes de la política, la moral y la estética y distingue entre, por un lado, las matemáticas, la física y el sentido común como de algunos elementos que permiten el acceso a la verdad objetiva y, por otro lado, la ética y la estética, para las que no es posible alcanzar esta verdad objetiva (Berlin 1999: 37-193).

Esta separación de aquello que es objetivo de lo que no es verdadero está conectada con el naufragio de las ilusiones. Primero fue el desengaño que representó la Revolución Francesa, después el de las invasiones napoleónicas y, junto a ellos, el desarrollo de la revolución industrial, portadora de miseria en los 
barrios marginales, de contaminación y de alienación del hombre con respecto a sí mismo y a la naturaleza. Estas desilusiones marcaron hasta tal grado la conciencia romántica que determinó que considerara inalcanzables los más profundos anhelos (Flaquer 1995: 4), que se desilusionara de la vida social (De Paz 1992: 68), y que instalara en su corazón la desesperanza, el pesimismo, la angustia respecto del futuro y los temores por la deshumanización, la reificación, la enajenación o la inautenticidad. Y, lo que parece más importante, que este pesimismo atroz le llevó, en último extremo, a creer que el autoconocimiento, la autoconciencia, han sido tan poco edificantes como el conocimiento de la realidad (Tollinchi 1989, II: 893 y s.).

El hombre y el mundo le parecen a los románticos limitados, lo que les empuja a perseguir lo ilimitado, el absoluto, la totalidad (Flaquer 1995: 15) y el infinito, y a distanciarse del espacio y del tiempo. Y es que sintieron la caducidad del tiempo y que sólo la muerte era infinita. Es decir, que creyeron que únicamente lograban la infinitud cuando morían, más allá de la vida y de la experiencia y fuera de las formas del espacio y del tiempo. No nos extrañe que desearan huir del mundo, distanciarse del tiempo y del espacio (De Paz 1992: 52 y s.), que buscaran lugares lejanos o que practicaran una evasión del presente en dirección al pasado o al futuro e, incluso, hacia sí mismos - como se ha visto- o hacia el arte (Arnaldo 1996a: 205). No sorprenda que esta evasión se vinculara igualmente con la persecución de lo auténtico o de lo verdadero y de las raíces y que revelara, en definitiva, el objetivo de alcanzar una realidad más profunda en los sentimientos, en la Historia y en la Naturaleza, los lugares no afectados por la Modernidad (Mosse 1997a: 18-29). Por todo ello, el romántico, que se opone a cualquier concepción que represente la realidad (Berlin 1999: 37-193), es un movimiento de disgusto respecto del «realismo» del mundo (De Paz 1992: 74).

\subsection{La estetización de la realidad}

Esta desazón respecto de la realidad se aprecia de una manera singular en el arte, concebido ahora con una novedosa actitud, pues intenta imponer un modelo estético a la realidad. Éste se logra a través de una serie de elementos caracterizadores: la pasión por la subjetividad y el paso de la mimesis a la expresión del sentimiento, la conciencia de que el mundo está fragmentado, la inalcanzabilidad del ideal y la desmaterialización o la huida de la realidad.

La pasión por la subjetividad caracteriza al arte romántico porque éste acaba con su carácter social y se convierte en la expresión de un individuo solitario, trágica y místicamente separado de los demás (De Paz 1992: 187). Además, el arte insiste en la individualidad — la pintura de retrato (Vaughan 1995: 52) y la autobiografía literaria (Tollinchi 1989, I: 256 y s.) — y en la condición interior del hombre que se halla a través de los sentimientos del corazón, que, si bien irracionales, son más legítimos que los pensamientos. Ello está unido a la transformación de la concepción estética desde la mimesis a la expresión que, aunque iniciada en el siglo XVIII, ahora prioriza las experiencias del pro- 
pio creador y se concentra en el proceso que la mente experimenta al crear. La conciencia de que el mundo está fragmentado, separado en esferas diferentes, también está presente en el arte romántico en el que el fragmento asume una importancia excepcional (De Paz 1992: 188 y 219). Por otra parte, un cierto sentimiento de desilusión, de melancolía y de inadaptación de los poetas, trae como consecuencia la ausencia de un estilo único y la instauración de un pluralismo cultural y artístico formado por la sucesión de nuevos estilos que divergían entre sí y que nunca terminaban de madurar del todo, convirtiendo al arte en un ideal inalcanzable. Y todo ello nos muestra que el arte romántico persigue la huida de la realidad, es decir, destruir la realidad visible para descubrir otra —mágica, sobrenatural o surreal (De Paz 1992: 188-9)—, y la desmaterialización, especialmente en la literatura —Goethe (1999: 144), Novalis (2004: 156) y Hölderlin (2003: 83-4) — y en la pintura — Joseph M.W. Turner, un precedente del arte abstracto (Honour 1994: 103; Vaughan 1995: 170).

\subsection{Somos herederos del Romanticismo en la concepción de la realidad}

El Romanticismo es un movimiento cultural, social e ideológico que consiguió revitalizar la cultura europea en todas sus manifestaciones sociales, políticas, artísticas, literarias, filosóficas, religiosas y científicas (De Paz 1992: 187192). Posiblemente constituye el movimiento que más ha transformado la vida occidental, pues su penetración en la conciencia — especialmente en lo que se refiere a la idea de la realidad- de los siglos XIX y XX es de tal profundidad que todos los demás movimientos se revelan menos trascendentes y ello sin olvidar que, además, están intensamente influidos por él (Berlin,1999:37-193). Entre sus herederos más importantes se encuentran, en el siglo XIX, el Nacionalismo y el Idealismo; a caballo entre los dos siglos, el Art Nouveau; y, en el siglo XX, el Expresionismo, el Fascismo y el Existencialismo francés. Voy a tratar ahora los influjos románticos en el siglo XIX y en el apartado dedicado a la Modernidad lo haré con los referidos al siglo XX.

El nacionalismo recibe del movimiento romántico el anhelo de orden en un mundo de cambios, ansia que será satisfecha a través de la búsqueda de las raíces y de la verdad que sólo se hallan tras las apariencias y mediante los mitos y los símbolos (Mosse 1997b: 29 y s.). Igualmente el Romanticismo se vincula con el Idealismo, a través de sus análisis acerca de la abstracción y de la huida de la realidad. Lo que sucede en Hegel, quien en Ciencia de la lógica considera que lo «finito es ideal»y, por consiguiente, lo único «real» es lo infinito, es decir, que el mundo en que nos movemos no es sino producto de la «idea» y que, por tanto, carece de cualquier «realidad» que no sea la derivada del propio pensamiento (Jarque 1996c: 206 ss.). También se conecta con el Romanticismo su concepto de «desgarro» —empleado en la Fenomenología del espiritu—, esto es, que el principio de subjetividad ha hundido tanto a la razón como al «sistema completo de la vida" (Solomon et al. 1999: 144; Habermas 1985: 27-8; Habermas 1989: 63-7). Igualmente Fichte cree que el fundamento de toda conciencia es la oposición, puesto que ésta está siempre dividida en contemplante 
y contemplado, en sujeto y objeto (Tollinchi 1989, I: 9-10.). Y del mismo modo Schiller se conecta con el Romanticismo cuando piensa que la Modernidad está dominada por el "espíritu de abstracción», por la conciencia de la escisión y por una experiencia estética que — como en los románticosestá asociada al distanciamiento de lo real (Schiller 1999: 145 y s.; Jarque 1996d: 233-5).

Será sobre todo después de 1870 , en el momento en el que resurjan el Romanticismo y el Idealismo, cuando ambos movimientos se vinculen con más fuerza al identificarse la realidad con la materia y al recuperarse lo irracional. Entonces van a dominar los que desean traspasar, por vía emocional y mística, la fachada del mundo material y los que se interesan por la conciencia de sí mismo del hombre. Esta disociación de la realidad vino acompañada del pesimismo y de la persecución de la individualidad, unida a un rechazo de la sociedad de masas, a una rebelión contra la sociedad positivista, a una renuncia a participar en los problemas de la sociedad, pasando del individualismo a la integración con el universo, el grupo o el Estado y del sentimiento al sentimentalismo. De este modo, se comprende que el Romanticismo acabe vinculándose con el amor a la naturaleza y a un pasado nacional idealizado. Así pues, los ideales románticos de libertad y de rebelión contra las convenciones se han pervertido y han generado los monstruos del sentimiento, especialmente cuando la religión o el nacionalismo prioricen la integración o la unidad romántica, en lugar de la libertad, y cuando se unan al racismo. Por eso, el talante romántico no ha contribuido a la libertad humana, ya que el deseo de trascendencia de la realidad, que no era sino un deseo de liberación absoluta del individuo, ha conducido en la práctica hacia actitudes totalitarias como el fascismo y el nacionalsocialismo, dos movimientos que reciben lo peor del Romanticismo.

\section{La Modernidad o la sustitución de la realidad por un paradigma tecnológico}

\subsection{La Modernidad, época de catástrofes y de esperanzas}

Como se va a poder comprobar, la visión que la Modernidad y la Posmodernidad poseen de la realidad es una herencia de los principios ilustrados y románticos a los que acabo de referirme, aunque naturalmente perfilada y desplegada con matices diferenciadores. En líneas generales, puede señalarse que continúa aumentando progresivamente la autoconciencia subjetiva, la separación del hombre y del mundo, la disolución de las certezas y el distanciamiento de la realidad, fenómenos que llegan a su consecución lógica durante la Posmodernidad.

La Modernidad propiamente dicha es el período que va, fundamentalmente, de 1890 a 1930 (Bell 1992: 117), aunque se alarga hasta la década de los 60, cuando una nueva fase a la que se le ha dado el nombre de Posmodernidad parece querer sustituirla. La Modernidad se caracteriza —al igual 
que la Ilustración y el Romanticismo- por ser una sociedad dual semiaristocrática y semidemocrática (Lipovetsky 2002: 126) o burguesa y democrática que explica tanto la polarización del pensamiento como el carácter conflictivo de los acontecimientos históricos. En efecto, es una época de catástrofes, ya que está situada entre dos guerras mundiales - la primera de las cuáles significó la caída de la civilización occidental del siglo XIX, esto es, de los imperios, del capitalismo mercantil y del liberalismo y, la segunda, el genocidio judío y las primeras bombas atómicas - y puesto que entre ambas guerras se dieron el auge del fascismo, del nacionalsocialismo y la Revolución de Octubre. Pero asimismo es, paradójicamente, un período de esperanza, como si tanta destrucción fuera necesaria para levantar un mundo mejor y, por eso, el arte de vanguardia —el que florece entre esas dos guerras de 1914 y 1945 - se convierte en una utopía social y, por eso, tras 1945 siguió una fase de crecimiento económico extraordinario que se conoce como «Edad de Oro» (Hobsbawm 2001: 29 y s.). Por lo demás, sobre esta dualización se asientan la idea de realidad que mantiene la Modernidad y los aspectos con los que está relacionada, especialmente con el derrocamiento de la cosmología racional tradicional -que trae aparejada la transformación del espacio, del tiempo, del sujeto y del objeto-, con la diferenciación de esferas — que da lugar a la disyunción entre la cultura y la estructura social—y con la disolución de las certezas.

\subsection{La transformación del espacio, del tiempo, del sujeto y del objeto}

La Modernidad supone una manera específica de entender la realidad por el derrocamiento de la "cosmología racional» del pensamiento occidental y, por tanto, por la transformación de sus ideas acerca del espacio, del tiempo, del sujeto y del objeto. Mientras que para Kant las categorías de espacio y tiempo son sintéticas a priori, esto es, constituyen las categorías fijas de la mente que permiten organizar la experiencia, para el historicismo de Wilhem Dilthey y, posteriormente, para el relativismo de Albert Einstein ni el espacio ni el tiempo son fijos, ya que cambian según los modos culturales (Bell 1992: 114) y según la perspectiva subjetiva (Russell 1984: 16). Por eso, las variaciones sobre el tiempo y el espacio dan lugar a una serie de efectos de amplio alcance sobre la propia sociedad.

Una de las características que definen a la Modernidad es que, frente a los pueblos antiguos que aspiraban ser (Eliade 1952: 22 y s.), apuesta por el devenir (Baumer 1985: 379 y s.), que ha triunfado en el pensamiento y en la vida cotidiana. Pero ha sido la ciencia la que ha reforzado empíricamente esta movilidad, puesto que ha demostrado la variabilidad de las especies - Darwin(Watson 2002: 31), el movimiento del planeta Tierra - la deriva continental de Wegener- (Strahler et al. 1994: 242 y s.) y el del universo - Einstein, Hubble, Leavitt, Friedmann y Lemaittre (Russell 1984: 132 y s.; Watson 2002: 149; Longair 1998: 1 y 36).

Esta idea del devenir conduce a que la realidad social se perciba a través de una serie de fragmentos fortuitos, como un estado de flujo incesante, y a que 
sean relacionales - la interacción y la asociación- los conceptos que mejor definen esa realidad social fluida - G. Simmel, Filosofía del dinero (1977) y W. Benjamin (Picó 1988: 21-23). Además, el dinamismo de la Modernidad deriva de la experiencia discontinua del espacio y del tiempo que exalta el presente, es decir, lo transitorio, lo elusivo y lo efímero (Thiebaut 1996: 313 y s.; Shattuck 1991: 292), lo que conduce a que la experiencia humana se manifieste en la inmediatez de las relaciones sociales (Picó 1988: 19) y perciba los acontecimientos como transitorios, fugaces y fortuitos. Esta fluidez desencadena también el desanclaje de los sistemas sociales y el reflexivo ordenamiento y reordenamiento de las relaciones sociales (Giddens 1993: 28), igualmente convertidas en fluidas y en transitorias por la discontinuidad o separación del tiempo y del espacio. Finalmente, la transformación de estas dos categorías ha afectado al arte, que pasa de la belleza universal a la belleza de lo transitorio, de la estética de la permanencia (basada en la creencia del ideal de belleza trascendente e inalterable) a una estética de la inmanencia y de la transitoriedad, cuyos valores centrales son el cambio y la novedad (Calinescu 1991: 15). Así pues, fue la respuesta al movimiento, al espacio y al cambio el que dio lugar a una nueva sintaxis del arte y a la dislocación de las formas tradicionales (Bell 1992: 58).

Y todo ello está vinculado con la modificación, estrechamente interconectada, del sujeto y del objeto. Si la subjetividad es el principio de toda Modernidad (Hegel), en el período al que denomino en propiedad Modernidad, el sujeto puede estar caracterizado, entre otros factores, por su racionalidad y contingencia, por su descentramiento, por su capacidad de autocrítica social, por su acotamiento y por su irreconciliable oposición al objeto. El individuo moderno es aquel que puede observar su propia observación y que se excluye operativamente del entorno y se incluye observativamente en él, y de ahí que la Modernidad esté marcada por la racionalidad y por la contingencia, pues todo se vuelve contingente cuando aquello que es observado depende de quién es observado (Luhmann 1997: 67-94). Igualmente se produce un descentramiento del sujeto moderno porque tienen lugar una serie de críticas desde diversos campos como la psicología - S. Freud - o la filosofía - Nietzsche, Horkheimer y Adorno- (Wellmer 1988: 117 y s.). La subjetividad moderna también conduce a la autocrítica social, especialmente en las vanguardias artísticas, donde la autoconciencia es crucial para su definición (Calinescu 1991: 104). La autoconciencia igualmente había caracterizado al Romanticismo, pero las vanguardias profundizan los planteamientos de éste al convertir la autoconciencia en una instancia autocrítica de la estructura social en la que se dan (Burger 1987: 12-23), es decir, al transformar la crisis social en una ecuación general de su cultura (Calinescu 1991: 131). Junto con la autoconciencia, el acotamiento del sujeto (Burger 1987: 11) define a la estética moderna en la medida en que la subjetividad ya no representa el objeto central del análisis sino el reflejo de la importancia del mundo social (Thiebaut 1996: 321). Finalmente, la subjetividad moderna se caracteriza por una irreconciliable oposición entre lo objetivado (el tiempo socialmente men- 
surable) y lo subjetivo (el tiempo creado, la durée imaginativa), constituyendo esta última identidad entre tiempo y yo uno de los fundamentos de la cultura (Calinescu 1991: 17). Y para que ello haya podido llegar a ser así, el objeto ha tenido que sufrir importantes variaciones. De nuevo la estética ha tenido un papel fundamental, ya que ha destruido la idea del objeto (Bell 1992: 117), a través del Expresionismo, del Simbolismo y del Cubismo, que revelan la multiplicidad paradójica del mundo, la ambigüedad y la incertidumbre y, en definitiva, que los objetos no tienen una forma absoluta, sino muchas dependiendo de la percepción (Picó 1988: 28).

\subsection{La disyunción entre la cultura y la estructura social}

Como se ha visto, la diferenciación entre distintas esferas, que llevó a una separación entre la cultura y la sociedad industrial y, por tanto, a la evasión de la misma, fue analizada en el siglo XVIII por Kant y en el XIX por Hegel y por la filosofía idealista alemana - Shiller, especialmente. A principios del siglo XX será también subrayada por Max Weber, quien caracterizó la Modernidad cultural como la separación de la razón sustantiva, expresada por la religión y por la metafísica, en tres esferas autónomas: la ciencia, la moralidad y el arte. Y si éstas se han diferenciado ha sido porque la visión del mundo unificado de la religión y de la metafísica se han disgregado. Por lo demás, cada una de ellas se halla bajo el control de especialistas, lo que aumenta la distancia entre la cultura de los expertos y la del público en general (Habermas 1984: 63-7). Igualmente, el sociólogo canadiense Daniel Bell ha recogido esta misma idea, en Las contradicciones culturales del capitalismo (1992: 11-63), donde distingue en el mundo capitalista ámbitos separados con ritmos de cambio diferentes - la estructura tecnoeconómica y la cultura - derivados de la influencia del hedonismo y del aflojamiento de los hilos que antaño mantenían unidas la cultura y la economía. Esta disgregación da lugar a una radical disyunción entre la cultura y la estructura social —que se observa en dos aspectos: en la autonomía de la cultura y en la mayor distancia entre la elite y la masa- y al rechazo mutuo entre la burguesía - que, aunque introduce el individualismo radical en la economía teme al individualismo experimental de la cultura- y el mundo de la cultura - que, a su vez, odia a la burguesía. La fragmentación de la Modernidad en esferas diferentes está también presente en las reflexiones de Mattei Calinescu, quien se dedica a esta cuestión en Cinco caras de la Modernidad. Modernismo, vanguardia, decadencia, kitsch, posmodernismo (1991: 16-50), donde señala que en algún momento de la primera mitad del siglo XIX se produce una irreversible separación entre la Modernidad como una fase de la historia de la civilización occidental — que es el producto del progreso científico y tecnológico, de la revolución industrial y de la economía arrolladoray la Modernidad estética. Finalmente, J. Habermas se refiere a la separación moderna, en "La Modernidad, un proyecto incompleto», donde distingue entre la Modernidad como idea y la Modernidad como proyecto (Habermas 1985: 28). 


\subsection{El cuestionamiento de la realidad, el derrocamiento de la materia y la disolución de las certezas}

Las transformaciones habidas en la idea del sujeto, así como la separación en esferas de la Modernidad están profundamente vinculadas con la disolución de las certezas, un fenómeno general que tiene posiblemente en la ciencia una impulsora fundamental. En efecto, se podría considerar el siglo XX como el "Siglo de la Ciencia», por la cantidad e importancia de los descubrimientos científicos que abarcan la totalidad del período (Sánchez 2000: 15 y s.), por su profunda aceptación y por ejercer una considerable influencia en las demás realizaciones humanas. De entre esas nociones que han sido impulsadas por la ciencia destacaría dos: el triunfo del devenir —al que ya he hecho referenciay el cuestionamiento de la realidad o derrocamiento de la materia o disolución de las certezas, fenómenos todos ellos interrelacionados que conducen a la sustitución de la realidad del ser humano por un paradigma tecnológico (Watson 2002: 14 y 809). Egon Friedel, en Historia cultural de los tiempos modernos, habla del «fin de la realidad», pero si esto ha sido así es porque la ciencia ha descubierto la incertidumbre del cosmos porque éste se prolonga hasta el infinito, porque su materia - los átomos - no pueden ser observados por su minúsculo tamaño y porque las estrellas no se encuentran fijas en el firmamento; la fragmentación del universo - la discontinuidad de la energía, Max Planck-; la pérdida del carácter fijo del tiempo y del espacio - la Teoría de la relatividad, Einstein-; la derrota de la materia, el acontecimiento más importante del siglo XX (Gilder 1989: 17); la desvinculación de la ideología; y la creciente importancia de la contingencia, la indeterminación, las posibilidades inesperadas, la codeterminación, la diversidad de la naturaleza y el escepticismo acerca de los comportamientos de la realidad para cuantificar sus fenómenos o para preverlos (Heisenberg y su Principio de incertidumbre, la Teoría del caos, la Teoría de las catástrofes, la Teoría de la complejidad de I. Prigogyne, la Teoría de la inverificabilidad matemática de Gödel y la Teoría de las estructuras disipativas; Woolley 1994: 191-224; Watson 2002: 35 y s.; Rifkin 2000: 253-4; Gubern 1996: 135; Mosse 1997b: 77 y s.).

Por todo ello, la ciencia ha roto con su tradicional finalidad, esto es, favorecer el ascenso de la materia, y amenaza con convertirse en un conjunto de postulados sobre la observación - ya no existe ningún universo real más allá de su observación - y no sobre la naturaleza real del universo. De este modo, ha minado gravemente la fe científica en una realidad externa y material y subvertido la que hasta aquí había sido la gran pretensión de la ciencia, la de revelar la realidad. En definitiva, la ciencia ha demostrado la debilidad del materialismo occidental y ha permitido que la realidad abandone el mundo físico y pase al mundo virtual.

Pero no ha sido la ciencia la única que ha conducido al alejamiento de la realidad, puesto que en ello también tienen un importante papel la filosofía y el arte. El existencialismo, por ejemplo, intenta huir de una realidad objetiva y no está interesado (con la excepción de Sartre) en compromisos externos con la 
sociedad, sino en el sentimiento interior de desconcierto del hombre; además, ve al ser como pensamiento (Mosse 1997b: 135 y s.). El arte, por su parte, se distancia de la realidad, en primer lugar, porque las vanguardias artísticas aspiran a eliminar el espacio, el tiempo, el sujeto y el objeto (Burger 1987: 10-29; Lambert 1969: 15 y s.) y a renunciar a la figuratividad, construyendo una forma a partir de unidades que no son entidades físicas sino relaciones conceptuales y negando, así, la objetividad a favor de la estructura — entendida ésta como un sistema de relaciones interiores a la obra (algo que había anunciado Diderot y el Romanticismo, pero que ahora se sistematiza) - y cuestionando su materialidad como objeto (Burger 1987: 17 y s.). En segundo lugar, porque el arte moderno avanza hacia su conceptualización, en la medida en que se desarrolla desde la forma a la idea (el concepto) o desde la estructuración de una nueva realidad hacia el proceso. Esta evolución, que tiene lugar en el conjunto del arte contemporáneo, consiste en un desplazamiento del interés de la realización del objeto hacia el proyecto operativo de éste o, lo que es lo mismo, en el paso de concebir la obra como una nueva estructura de la realidad a poner un mayor hincapié en el acto artístico mismo (Block 1992: 142; Guasch 2002: 20 y s.). Y en tercer lugar, el Art Nouveau, el Expresionismo y el Arte Abstracto expresan un deseo abierto de abandonar la realidad. El Art Nouveau es un movimiento que protesta contra el Romanticismo, pero que acaba como él divorciándose de la realidad. Y es que, aunque según su concepción, la belleza debe plantearse de un modo racional, termina transformándose en un arte fantástico y escapista que expresa el rechazo del ideal racional y científico modernos. Igualmente los expresionistas — que en esto son los más directos receptores de los postulados artísticos románticos - no deseaban pintar el mundo tal y como los hombres lo veían sino penetrar más allá de la realidad, en lo que ellos creían que había detrás. Por eso, impulsados por la rebelión contra la razón, revivieron lo primitivo del hombre - concebido como la auténtica realidad-, rechazaron la cultura burguesa y reaccionaron intensamente contra el materialismo (Mosse 1997b: 11 y s.). Finalmente, el arte abstracto es el que lleva más lejos este abandono de la realidad (Roche 2004: 983 y s.), en la medida en que uno de sus caracteres más importantes es su propuesta de creación de una nueva realidad, pues no mantiene una relación aparente con el mundo exterior (Moszynska 1999: 7) ni es descriptivo ni tiene apariencias naturalistas (Harrison et al. 1998: 216). Por tanto, se puede decir que ha perdido su materialidad, su realidad misma, y que es una producción mental (Lambert 1969: 11).

En unión a la ciencia, a la filosofía y al arte modernos, la sociedad en su conjunto también manifiesta la evasión de la realidad. Es lo que sucede en el fascismo y en el nacionalsocialismo, con su búsqueda del ideal en un pasado que no conocía los problemas de la era industrial (Mosse 1997b: 145 y s.). Y lo que ocurre con la economía, ya que, al convertirse la propiedad en capital, éste ya no se manifiesta en bienes específicos sino en una suma abstracta útil (Heilbroner et al. 1999: 46-154). Por su parte, el dinero ha seguido igualmente un paulatino proceso de abstracción y de desmaterialización (Sánchez 2004: 251 y s.), puesto que ha sustituido el sistema de trueque de objeto por objeto 
para constituirse en un intermediario abstracto de la relación económica. Aunque durante mucho tiempo las formas del dinero más permanentes y generalizadas han sido materiales físicos, el cobre, el oro y la plata, fueron progresiva y parcialmente reemplazados, primero por las letras y otros sistemas cambiarios y, más tarde, en la primera mitad del siglo XX, por los talones bancarios (Woolley 1994: 116). Finalmente, a este proceso de abstracción y de desmaterialización económica, le ha acompañado la conciencia de que la mercancía y la moda construyen una realidad ilusoria (Walter Benjamín) y de que la vida se está transformando en un sistema de brillantes apariencias por el escaparate de la moda y por el triunfo de la decoración y del diseño (Ch. Baudelaire, El pintor de la vida moderna).

\section{La Posmodernidad o la venta de la realidad}

\section{1. ¿Un periodo diferente?}

La Posmodernidad es el tiempo posterior a la crisis del petróleo de 1973 y que llega hasta nuestros días. Constituye una nueva fase de descomposición, de incertidumbre, de sucesivas crisis y de derrumbamiento, no sólo porque acaban las últimas colonias, sino también por el final del socialismo y, con él, de las ideologías que han dejado al sistema capitalista prácticamente solo en la escena del poder económico mundial (Hobsbawm 2001: 403 y s.). Pero debemos ser muy prudentes y no afirmar taxativamente que estemos en un período diferente al de la Modernidad, puesto que carecemos de pruebas suficientes para afirmar que nuestra condición sea posmoderna (Lyon 1997: 21 y 151), lo que no es óbice para reconocer que nuestro tiempo muestra, con respecto a aquella etapa, algunos matices peculiares. Por ejemplo, es posible que describa un estilo particular que conecta novedosos rasgos formales de la cultura con la aparición de un nuevo tipo de vida social y de orden económico, llámese modernización, sociedad posindustrial o de consumo, capitalismo multinacional, tardocapitalismo, capitalismo del acceso, etc. (Jameson 1985: 167).

\subsection{El desvanecimiento del sujeto, la inundación de la realidad por la cultura $y$ el devoramiento de la verdad}

La Posmodernidad culmina el proceso, iniciado en el Renacimiento y consolidado durante la Ilustración y el Romanticismo, en relación con los fenómenos interrelacionados a los que me estoy refiriendo en este artículo: el subjetivismo, la fragmentación del hombre y del mundo, la disolución de las certezas y el distanciamiento de la realidad. Por lo que se refiere al sujeto, la Posmodernidad lleva consigo una variación, pues en esta fase se produce el rechazo de la subjetividad romántica, lo que significa el desvanecimiento del sujeto - Foucault, el estructuralismo, el neopragmatismo de Rorthy y la deconstrucción de De Man y de Derrida (Thiebaut 1996: 321-2)—, su desaparición o su muerte (Jameson 1998: 228) y un desplazamiento de la alienación del 
sujeto hacia su fragmentación (Jameson 1991: 36-41). Ello está unido a lo que le ha sucedido al objeto, igualmente destruido (Jameson 1998: 228) o transformado en el arte por una especie de nueva revuelta surrealista que siente la necesidad de "cambiar el objeto mismo» (Foster 1985: 9-10). Por tanto, en la Posmodernidad, los conceptos metafísicos de sujeto y objeto han perdido peso (Vattimo 1995). Junto con el desvanecimiento del sujeto, se produce también el de la complejidad de la racionalidad moderna, en tanto que la individualidad dispersa las articulaciones de sentido y se resaltan los nuevos factores técnicos, mediáticos e informáticos mediante los que se conforma (Thiebaut 1996: 312 y s.). Finalmente, también la polarización característica de la Modernidad (Berman 1991: 243 y s.) ha sido sustituida por la simplificación (Roche [en prensa]).

Pero además, ahora la cultura lo inunda todo (Féher 1989: 9-12), es decir, invade toda la realidad, estetizándola y convirtiéndose, así, en una extensión de lo que hicieron las vanguardias artísticas —el Posmodernismo es, en gran parte, un Modernismo estético o profundamente enraizado en él (Wellmer 1988: 123). De este modo, la cultura se ha constituido en una auténtica segunda naturaleza y en la norma hegemónica o en la lógica cultural dominante (Jameson 1985: 177; 1991: 16-21; 1998: 10). Esta ampliación del ámbito de la cultura es paralela a su solapamiento con la economía (Connor 1996: 49; Lyon 1997: 150; Lyotard 1984: 10-3; Jameson 1998: 22 y 214-227), dando lugar a que ambas digan lo mismo, a que se eclipse la distinción entre la base y la superestructura, a que se borren las distancias entre la cosa y el concepto o a que se difuminen los límites de las separaciones clave, como, por ejemplo, la cultura superior de la cultura de masas (Jameson 1985: 166). No extrañe que las representaciones «realistas» sólo puedan rememorar la realidad con la nostalgia o con la burla, pues ese realismo se adapta a todas las tendencias al igual que el capital se adecua a todas las «necesidades», y que el collage (Lyon 1997: 23) o el eclecticismo se hayan convertido en la base de la cultura general contemporánea (Lyotard 1985: 15-8). Como no puede sorprender que el arte posmoderno se haya comercializado hasta tal extremo que transforme la racionalidad formal moderna en una comercialización generalizada. En efecto, la identificación de los valores estéticos y sociales de las vanguardias artísticas con la racionalidad y el progreso técnico-industriales ha dado paso a la comercialización del arte, a su sujeción a los medios de comunicación de masas, a su integración con los intereses económicos y políticos y a la pérdida de la dimensión autónoma y crítica con respecto al poder. Es posible que esta privación de los contenidos transgresores y utópicos, que llega a su máxima intensidad en el arte posmoderno, represente un factor de la decadencia o de la crisis del arte contemporáneo y, en cualquier caso, refleja un modo de ser y de vivir y, sobre todo, los efectos empobrecedores de la vida y de su experiencia subjetiva como efecto de su racionalización tecnológica en los países industrializados. En este sentido, la reducción de la forma artística que la acompaña es un elemento significativo del vacío cultural de nuestro momento histórico (Subirats 1989: $19-44$ y 152 ). 
Una vez que la Modernidad hubo sacrificado la verdad, a la Posmodernidad lo único que le queda por hacer es vivir en la duda y de ahí que ésta sea una época que, huyendo del dogmatismo, del autoritarismo y del absolutismo, ha caído en un relativismo epistemológico en el que todas las teorías son igualmente respetables y en el que toda verdad ha quedado devorada. Si tenemos en cuenta, por otra parte, que el hombre posmoderno —al igual que el ilustrado y el romántico- está siempre en camino, que es naturaleza físico-social abierta al devenir y a lo posible (Fullat 2002: 28 y s.), entenderemos entonces que «al final del ser no quede nada, tan sólo el Nihilismo» (Vattimo 1995: 24 y s.) y que se instale una existencia incierta y carente de certezas en la que «la gente se traga todas las mentiras» (Fernández-Armesto 1999: 177 y s.), la primera de ellas que la realidad no existe.

\subsection{La realidad se desrealiza, se teatraliza, se virtualiza, se desmaterializa y se conceptualiza}

Así es, en la Posmodernidad la realidad misma es cuestionada (Lyon 1997: 12) en tanto que se desrealiza, se teatraliza, se virtualiza, se desmaterializa y se conceptualiza. El mundo se desrealiza (Vattimo 1995: 156 y s.) porque el capitalismo tiene por sí solo el poder de desrealizar los objetos habituales y los papeles de la vida social y de las instituciones, porque ha transformado el valor de uso en valor de cambio, es decir, por la reducción del ser a valor de cambio y porque ha devorado lo físico. Aunque la era industrial ha tenido que ver también con el descubrimiento de la realidad, la industria transformadora de la naturaleza ha ayudado a que el mundo sea cada vez más artificial y menos real - como hemos visto que sucedía en el Romanticismo y en la Modernidady ha conducido a que los negocios terminen secuestrando el término «real», como una expresión que vende (Woolley 1994: XV-XIX). Y es que el capitalismo se ve abocado, por su constante exigencia de autorrenovación, de crecimiento, de sustitución de todo lo viejo por lo nuevo, a devorar el mundo físico (Berman 1991: 288).

La realidad es teatralizada por estar menos netamente dividida entre lo verdadero y la ficción (Woolley 1994: XV-XIX) y porque de ser una fábrica gigantesca se está convirtiendo en un gran teatro, en la medida en que la experiencia de vida simulada en el ciberespacio — un espacio imaginario que existe sólo en el interior de los ordenadores- es, en el fondo, una experiencia teatral y en la medida en que ese espacio imaginario es un nuevo escenario mundial (Rifkin 2000: 15 y s.). A ello ayuda considerablemente la publicidad, que es la vida del capitalismo y al mismo tiempo su sueño (Berger 1975: 149 y s.), ya que su objetivo es que el espectador se sienta insatisfecho con su modo de vida actual, siendo el presente insuficiente por definición y capitalizando indefinidamente la consecución del futuro. Porque a la publicidad no le interesa cumplir sus promesas, sino corresponderse con los deseos y las fantasías de los compradores, por lo que su verdadero campo de aplicación no es la realidad sino los ensueños. De este modo, el mundo entero se convierte en 
un escenario donde se cumple la promesa publicitaria de una buena vida dominada por el consumo.

La Posmodernidad se virtualiza ${ }^{2}$, sobretodo en la economía, en la ciencia y en la tecnología y en la cultura. En la economía, cuando se acelere su abstracción en las últimas décadas del siglo XX — sobre todo, a partir de 1973, con la globalización económica, con el incremento del volumen de los flujos financieros internacionales y con el aumento, a través de él, de la especulación en las finanzas mundiales (Heilbroner et al. 1999: 46 y s.) — y se consume la última fase de abstracción que llamamos virtual, en la que los mercados dejan sitio a las redes y el acceso sustituye cada vez más a la propiedad (Rifkin 2000: 14 y s.). En la ciencia y en la tecnología, la virtualización se pone de manifiesto especialmente con la introducción de la computación, que es, a la vez, una tecnología y una ciencia (Woolley 1994: 225-6). El ordenador representa un espejo de las ideas científicas provenientes de las matemáticas pero, en especial, de dos de ellas: el universo es computable (Gubern 1996: 134) y el abandono de la realidad física y su sustitución por una realidad mental, abstracta, inmaterial y virtual (Woolley 1994: 47 y s.). Esta última idea el ordenador la aplica, a través de su maquinaria, de su funcionamiento y de la imagen virtual que genera (Roche 2004: 996 y s.), de manera que la informática consiste en el «movimiento global de ingrávidos bits a la velocidad de la luz» y en la sustitución del átomo por el bit, de lo físico por lo digital (Terceiro 1996: 27 y s.). En último lugar, la virtualidad inunda la cultura, puesto que en una sociedad que ha generalizado el valor del cambio hasta el punto de desvanecer todo recuerdo del valor de uso, se materializa la cultura del simulacro (Baudrillard 1984), siendo el simulacro la copia idéntica de la que nunca ha existido el original (Jameson 1991: 45).

La Posmodernidad se desmaterializa porque la economía entra en una fase de ingravidez y porque el dinero se desmaterializa (Sánchez 2004: 340) al introducirse las tarjetas de crédito y las transferencias por el ordenador (Rifkin 2000: 49 y s.) cada vez con una implantación más numerosa, como la de las propias operaciones en este aparato (Woolley 1994: 116) que también se encuentra entre los innumerables productos que en la sociedad contemporánea se desmaterializan y que encabezan el camino hacia la ingravidez (Rifkin 2000: 50).

Finalmente, la Posmodernidad se conceptualiza en el mercado y en el arte. En el mercado porque tiene lugar la desaparición del lugar físico y porque existe una tendencia a la identificación de la mercancía con su imagen y una simbiosis más íntima entre el mercado y los mass media. Frente al Modernismo, cuyo rasgo más profundo y fundamental es su hostilidad hacia el mercado, la Posmodernidad, por el contrario, lo afirma. Pero en esta confirmación tiene lugar un profundo cambio, pues se pasa de la producción industrial a la producción cultural (el turismo, los parques temáticos, la moda y la cocina, los

2. La realidad virtual es un concepto que está interesando a la sociología, como puede apreciarse en la definición y en la bibliografía que sobre ella incluye el Diccionario de sociología, de Octavio Uña Juárez y de Alfredo Hernández Sánchez, p. 1181-2. 
juegos y deportes profesionales, la música, el cine, la televisión y los mundos virtuales...), transformándose el capital intelectual en la fuerza motriz de la nueva era y en lo más codiciado. Son los conceptos, las ideas, las imágenes y no las cosas las que constituyen los auténticos artículos con valor en la nueva economía - las franquicias-, una economía que ya no convierte a la fábrica en su metáfora y que ha tenido en el Arte Abstracto, en el Constructivismo, en la Bauhaus y en el Neoplasticismo sus precedentes y también en la máquina de ilusiones de Hollywood, el modelo más importante para este capitalismo cultural. Este proceso de conceptualización se observa igualmente en el arte posmoderno porque en él se producen una serie de retornos del arte conceptual moderno - el Conceptual y el Minimal Art_, mediante toda una variedad de prácticas neoconceptuales (Guasch 2002).

\section{Conclusiones: el doble rostro científico-tecnológico y hedonista- consumista de la Posmodernidad}

1. ${ }^{\text {a }}$ En coherencia con los objetivos y con las bases teóricas y metodológicas planteados en este artículo, creo haber podido mostrar que la historia de la idea de la realidad en Occidente desde la Ilustración hasta hoy se ha ido gestando durante ese largo periodo en la mente de los intelectuales filósofos, artistas, literatos, científicos-, pero ha terminado siendo absorbida por las prácticas sociales del conjunto de la sociedad posmoderna. No cabe duda que la fusión de la cultura de masas con la de las élites, una psicología social hedonista y el solapamiento de la cultura con la economía se encuentran en la base de esa asimilación generalizada.

2. ${ }^{\text {a }}$ He pretendido poner de manifiesto también que la cultura ha tenido un decisivo papel en la construcción de la realidad social, fundamentalmente en su definición, actuando a través de una dialéctica en la que la permanencia y el cambio han ido de la mano, esto es, que la cultura al mismo tiempo ha estructurado y desestructurado la realidad: estructurado porque ha conducido hacia una nueva concepción de la misma, más mental, subjetiva y evanescente y desestructurado porque ha tenido que disolver la vieja materialidad que la conformaba.

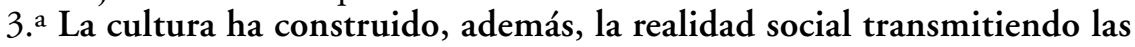
ideas entre los distintos campos culturales - filosofía, arte, ciencia...si bien en ese proceso de comunicación no todos ellos han tenido el mismo peso. Si en un primer momento fue la religión la que proporcionó el sustento teórico de la idea de realidad, a partir del Renacimiento será la filosofía la que asuma dicha tarea, lo que hará sobre todo durante la Ilustración. Desde fines del siglo XVIII hasta las primeras décadas del XX será la estética la que desarrollará esa función y la que invadirá todos los extremos de la vida, lo que tal vez logra con toda su intensidad en la Posmodernidad. Además, en el siglo XVII y especialmente a principios del XX también la ciencia surgirá con fuerza y aspirará a asumir un rol protagonista, algo que ha conseguido a lo largo del último siglo en conjunción con la tecnología. 
Junto a ellas, la economía siempre ha mantenido un poder considerable de influencia en tanto que ella ha sido una de las fuerzas poderosas que han alejado al hombre de la naturaleza y que lo ha situado en el camino de la abstracción. Sinceramente, no sabría determinar si, en esa senda de alejamiento de la realidad a la que me vengo refiriendo, primero fue la economía - la tesis de Marx - o antes estuvo la cultura - la teoría de Weber. Es probable que los influjos mutuos hayan sido tan continuos y complejos que hacen casi imposible dar prioridad a un campo o al otro. Pero en cualquier caso, lo que sí es evidente es que, en la Posmodernidad, la realidad ha sido entregada desde el pensamiento, desde la estética y desde la ciencia a un orden económico dominante que, tras la caída casi total del ámbito socialista, se ha enseñoreado del mundo y también de la propia realidad.

$4{ }^{a}$ La transmisión de las ideas entre los distintos campos culturales analizados ha tejido una tupida malla que forma la concepción del mundo occidental. Una cosmovisión sustentada, ante todo, en un creciente subjetivismo, que es el que ha posibilitado el proceso de destrucción y de sustitución de la realidad. Durante todo este proceso, el sujeto ha crecido en detrimento del objeto, que ha acabado destruido por el empuje de aquél, lo que a su vez ha traído consecuencias para el propio sujeto. Y es que sin el objeto, sin ese límite, sin ese espejo en el que se miraba, el sujeto ha terminado por no reconocerse, por profundizar en su problemática, por acotarse, por descentrarse, por cuestionarse a sí mismo. Y, así, exhausto ante tanta energía desplegada, ante tanta pasión y voluntad de poder, se ha quedado a las puertas de su desvanecimiento y de o no creer en sí mismo o de autodestruirse. Este final parecía inevitable desde que Kant concibiera la naturaleza del hombre no como ser sustancia, sino esencial dinamismo y autodesarrollo, y en el momento en el que la Posmodernidad lo definió como un ser humano siempre en camino, como deber-ser, naturaleza abierta al devenir y a lo posible. Igualmente se podía intuir por el carácter del hombre moderno, profundamente insatisfecho por naturaleza, como le sucedía al Don Juan de Mozart y al Fausto de Goethe (1999: $84-5$ y 121 y 420), probablemente prototipos de la actual publicidad que trabaja sobre la insatisfacción por definición. Pero a mí me parece que el sujeto también ha sido devorado por el propio capitalismo y la tecnificación de la vida que le es afín.

5. ${ }^{\text {a }}$ El creciente subjetivismo, unido al devenir de los acontecimientos, explica el avance paulatino hacia una mayor separación entre el hombre y el mundo y entre la sociedad y el propio individuo, hacia una mayor abstracción, hacia la disolución de las certezas y hacia un mayor alejamiento de la realidad. Fue Descartes quien abrió el camino, pero será sobre todo en la Ilustración y en el Romanticismo cuando se construyan los cimientos más sólidos en este proceso de distanciamiento que culminará en la sociedad contemporánea moderna y posmoderna. Es cierto que en la Ilustración domina el apego a la realidad y el deseo de compaginar la cultura con los cambios económicos producidos por la revolución indus- 
trial, pero se empieza a cuestionar esa realidad en la medida en que la Ilustración es también desgarradora, autocrítica y con tendencia a disolver las certezas. No podía ser de otra manera porque nos encontramos ante el final de la aristocracia y de la monarquía absoluta y ante el inicio de una sociedad de clases en la que la burguesía va a poseer cada vez más poder. Estamos asistiendo a los últimos momentos del dominio de lo comunitario sobre lo individual, de la tradición frente a la modernización, de la admiración sobre el rechazo de la industrialización y de la realidad sobre la irrealidad. Pero todo esto se va a invertir durante el Romanticismo, época en la que se consolida definitivamente el deseo de cambio que, a partir de ahora, será más importante que la continuidad. Además, los románticos, impulsados por la pasión por la subjetividad, por la separación entre el hombre y el mundo y entre la cultura y la economía, por el naufragio de las ilusiones y por el deseo de evadirse de la realidad, ya no consideran a ésta como determinante de la actuación humana. Es verdad que todavía sienten añoranza por el viejo mundo, por la realidad material, pero saben que ésta nunca más volverá porque el capitalismo lo devora todo, lo desvanece ${ }^{3}$ todo y, precisamente por eso, fueron presos de una nostalgia melancólica difícil de superar. La Modernidad y la Posmodernidad son hijas de la Ilustración y del Romanticismo, de la razón y del sentimiento, pero también de los monstruos de la razón y del sentimiento. Durante estos períodos tuvieron lugar dos grandes guerras, la caída de mundos sólidamente asentados como los imperios o el orbe socialista y el recuerdo terrible de todos los acontecimientos de un siglo no menos bárbaro que cualquier otro. De ahí que, en paralelo al rechazo a un mundo tan monstruoso, la conciencia subjetiva creciera hasta su máxima intensidad y la valoración de la realidad disminuyera hasta el mínimo posible. En la Modernidad, se ha sustituido la realidad por un paradigma tecnológico al derrocarse la cosmología racional con la transformación del espacio, del tiempo, del sujeto y del objeto, se ha efectuado una disyunción entre la cultura y la estructura social, se ha derrocado a la materia y se han disuelto las certezas. La Posmodernidad, por su parte, ha acabado venciendo a la realidad y, si ello ha sucedido así, ha sido porque no ha podido soportar tanta profundidad, tanto dolor, tanta monstruosidad, tanto remordimiento. Ello explica que hayan desparecido las ideologías, las clases sociales y su concomitante polarización, que el sujeto se haya desvanecido, que la cultura haya inundado toda la realidad, que se haya unido al capitalismo y que la duda se haya instalado cómo-

3. Escribe Marx, en el Manifiesto comunista, p. 43, que «todo lo estamental y estable se evapora, todo lo consagrado se desacraliza, y los hombres se ven finalmente obligados a contemplar con ojos desapasionados su posición frente a la vida, sus relaciones mutuas». Es la misma sensación de que todo lo sólido se desvanece en el aire que ya fue observada por Shakespeare, en La tempestad, acto 4, escena 1, 1.150, y recientemente por Marshall Berman, en su libro Todo lo sólido se desvanece en el aire. La experiencia de la modernidad. 
damente en la vida y en las conciencias permitiéndose creer todas las mentiras y, entre ellas, que la realidad no existe. Así se explica que ésta haya sufrido sus últimos embates, se haya desrealizado, teatralizado, virtualizado, desmaterializado y conceptualizado, cerrándose así un largo desarrollo iniciado al menos durante la Ilustración.

6. ${ }^{a}$ Este largo proceso ha desembocado en la Posmodernidad en, al menos, dos modelos sustitutivos de la realidad: el que yo llamaría modelo tecnológico o virtual y el modelo estético o del simulacro. El primero procede de la ciencia y de la tecnología y puede observarse en la realidad virtual, en la imagen infográfica y en la economía del acceso generadas por los ordenadores y también en ciudades como Tokio, en las que el ciudadano está tan rodeado de tecnología que se hace impensable, imposible, la subsistencia sin ella. El segundo, que procede de la arquitectura, del urbanismo y de la fábrica de sueños de Hollywood y que ha sido teorizado por la filosofía, caracteriza mejor a la ciudad de las Vegas con sus recreaciones de ensueño que viajan a culturas y a tiempos distantes y a los parques de ocio y a los centros comerciales donde abundan los decorados de cartón piedra. En ambos modelos — que pueden coexistir- la presencia, el dominio de la economía, es avasallador, pues es la que logra fusionar la ciencia con la estética y la filosofía. Pero siempre a costa de que la realidad se convierta en una mercancía más y, como ella, en un objeto a la venta.

7. a Estos dos modelos sustitutivos de la realidad revelan un hombre moderno con un rostro científico-tecnológico acompañado de otro con carácter hedonista o consumista. Yo entiendo que ese doble rostro conforma una máscara trágico-cómica que nos obliga a analizar el fenómeno de forma ambivalente. Así es, los sociólogos debemos admitir que esta conversión es alegremente aceptada por la inmensa mayoría de la sociedad, pero también criticar lo que oculta, es decir, que el sujeto y la realidad han sido convertidos en mercancías y que, por tanto, han sido afectados por el traspaso del valor de uso a valor de cambio, un valor cada vez más en auge por la propia naturaleza del capitalismo y por la sociedad del devenir. Y si ello ha sido así es porque el hombre posmoderno, que recibe un pesado legado histórico, se ha hecho consciente - como el romántico- de que la autoconciencia o el autoconocimiento son tan poco edificantes como lo es el conocimiento de la realidad. Y de este modo hereda un atroz nihilismo que sustituye la tradicional y compleja relación entre el hombre y el mundo por un gran vacío existencial en el que flotan azarosa y discontinuamente el sujeto y el mundo, que, como los átomos, son tan minúsculos que no pueden ni ser observados ni observarse. En definitiva, el distanciamiento y la venta de la realidad ha traído como consecuencia el empequeñecimiento de lo humano, de lo social, y quizás, por ello, no tengamos tantos motivos para la alegría. 


\section{Bibliografía}

ARnAldo, Javier (1996a). «El movimiento romántico». En BOZAL, Valeriano. Historia de las ideas estéticas y de las teorías artísticas contemporáneas. Vol. I. Madrid: Visor.

- (1996b). "Ilustración y enciclopedismo». En BozAL, Valeriano. Historia de las ideas estéticas y de las teorías artísticas contemporáneas. Vol. I. Madrid: Visor.

BArboza MarTíneZ, Amalia (2002). «Sobre el uso de la imagen en la sociología de la cultura. El método de la interpretación documental del sociólogo Karl Mannheim». En Amador Carretero, Pilar; Robledano, Jesús; Ruiz Franco, Rosario. Imagen, Cultura y Tecnología. Madrid: Universidad Carlos III.

- (2005). «Las imágenes como objeto y técnica de análisis en la sociología: el método de la interpretación documental». En RoCHE CÁRCEL, Juan A.; Oliver Narbona, Manuel (eds.). La cultura entre el conflicto y el diálogo. Publicaciones de la Universidad de Alicante.

BAUdrillard, Jean (1984). Cultura y Simulacro. Barcelona: Kairós.

BAUMER, Franklin L. (1985). El pensamiento europeo moderno. Continuidad y cambio en las ideas, 1600-1959. México: FCE.

BELTRÁn, Miguel (2003). La realidad social. Madrid: Tecnos.

BELL, Daniel (1992). Las contradicciones culturales del capitalismo. Madrid: Alianza. BELlO, Eduardo (1997). La aventura de la razón: el pensamiento ilustrado. Madrid: Akal.

Berger, J. (1975). Modos de ver. Barcelona: Gustavo Gili.

Berger, Peter; LuCKMAnN, Thomas (2001). La construcción social de la realidad.

Buenos Aires: Amorrortu editores.

BERLIN, Isaiah (1999). Las raices del romanticismo. Madrid: Taurus.

BERMAN, Marshall (1991). Todo lo sólido se desvanece en el aire. La experiencia de la modernidad. Madrid: Siglo XXI.

Block, Cor (1992). Historia del arte abstracto (1900-1960). Madrid: Cátedra.

BLOOM, Harold (1995). El canon occidental. Barcelona: Anagrama.

Bourdieu, Pierre (1982). Ce que parler veut dire. L'écomomie des échanges lingüistiques. París: Fayard.

BozAL, Valeriano (1996a). «Inmanuel Kant». En BozAL, Valeriano. Historia de las ideas estéticas y de las teorías artísticas contemporáneas. Vol. I. Madrid: Visor.

- (1996b). "Orígenes de la estética moderna». En Bozal, Valeriano. Historia de las ideas estéticas y de las teorías artísticas contemporáneas. Vol. I. Madrid: Visor.

Bunge, Mario (1985). La investigación cientifica. Barcelona: Ariel.

Burger, Peter (1987). Teoría de la vanguardia. Barcelona: Península.

BurKHARD, Jacob (1962). La cultura del Renacimiento en Italia. Buenos Aires: Losada.

Calinescu, Mattei (1991). Cinco caras de la Modernidad. Modernismo, vanguardia, decadencia, kitsch, posmodernismo. Madrid: Tecnos.

CASSIRER, Ernst (1950). Filosofía de la Ilustración. México: FCE.

CONNOR, Steven (1996). Cultura Postmoderna. Introducción a las teorías de la contemporaneidad. Madrid: Akal.

De PAZ, Alfredo (1992). La revolución romántica. Poéticas, estéticas, ideologías. Madrid: Tecnos.

DeborD, Guy (2003). La sociedad del espectáculo. Valencia: Pre-textos.

DiDEROT, Denis (1983). Escritos filosóficos. Madrid: Editora Nacional.

- (1994). Escritos sobre arte. Madrid: Editorial Siruela. 
DURKHEIM, Émile (1985). Las reglas del método sociológico. Barcelona: Ediciones Orbis. Eliade, Mircea (1952). El mito del eterno retorno. Buenos Aires: Emecé Editores.

FEHER, Ferenc; Heller, Agnes (1989). Politicas de la postmodernidad. Ensayos de crítica cultural. Barcelona: Península.

FERnÁNDEZ-ARMESTO, Felipe (1999). Historia de la verdad y una guía para perplejos. Barcelona: Herder.

FERrATER Mora, José (1986). Diccionario de filosofía. Madrid: Alianza.

FLAQUER, Jaume (1995). Hegel y el Romanticismo. La importancia de la relación. Sant Cugat del Vallès: Institut de Filologia Fonamental.

Foster, Hal (1985). La posmodernidad. Barcelona: Kairós.

Fullat, Octavi (2002). El siglo postmoderno (1900-2001). Barcelona: Crítica.

Giddens, Anthony (1993). Consecuencias de la Modernidad. Madrid: Alianza.

GILDER, George (1989). Microcosm: The Quantum Revolution in Economics and Technology. Nueva York: Simón \& Schuster.

Goethe (1999). Fausto. Madrid: Cátedra.

GOFFMAN, Erving (1981). La presentación de la persona en la vida cotidiana. Buenos Aires: Amorrortu Editores.

GuASCH, Anna Maria (2002). El arte último del siglo XX. Del posminimalismo a lo multicultural. Madrid: Alianza Forma.

GUBERn, Román (1996). Del bisonte a la realidad virtual. La escena y el laberinto. Barcelona: Anagrama.

Habermas, Jürgen (1984). Ciencia y técnica como ideología. Madrid: Tecnos.

- (1985). "La modernidad, un proyecto incompleto». En FosTER, Hal. La Posmodernidad. Barcelona: Kairós.

- (1989). El discurso filosófico de la modernidad. Madrid: Taurus.

Harrison, Charles; Frascina, Francis; Perry, Gil (1998). Primitivismo, Cubismo y Abstracción. Los primeros años del siglo XX. Madrid: Akal.

HeIlbroner, R.; MilberG, W. (1999). La evolución de la sociedad económica. México: Prentice May.

HoBSBAWM, Eric (2001). Historia del siglo XX. Barcelona: Crítica.

Hölderlin, F. (2003). Hiperión o el eremita en Grecia. Madrid: Gredos.

HonOur, Hugh (1994). El Romanticismo. Madrid: Alianza Forma.

IGLESIAS, Carmen (1999). Razón y sentimiento en el siglo XVIII. Madrid: Real Academia de la Historia.

JAMESON, F. (1985). «Posmodernismo y sociedad de consumo». En FosTer, Hal. La Posmodernidad. Barcelona: Kairós.

- (1991). El posmodernismo o la lógica cultural del capitalismo avanzado. Barcelona: Paidós.

- (1998). Teoría de la Postmodernidad. Madrid: Trotta.

JARQUE, Vicente (1996a). "Johann Gottfried Herder». En BoZAL, Valeriano. Historia de las ideas estéticas y de las teorías artísticas contemporáneas. Vol. I. Madrid: Visor.

- (1996b). "Charles Baudelaire». En Bozal, Valeriano. Historia de las ideas estéticas $y$ de las teorías artísticas contemporáneas. Vol. I. Madrid: Visor.

- (1996c). "Filosofía idealista y romanticismo». En BOZAL, Valeriano. Historia de las ideas estéticas y de las teorias artísticas contemporáneas. Vol. I. Madrid: Visor.

- (1996d). "Friedrich Schiller». En Bozal, Valeriano. Historia de las ideas estéticas y de las teorias artísticas contemporáneas. Vol. I. Madrid: Visor.

- (1996e). «G.W.F. Hegel». En BozAL, Valeriano. Historia de las ideas estéticas y de las teorías artísticas contemporáneas. Vol. I. Madrid: Visor. 
- (1996f). "Gotthold Ephrain Lessing». En BOZAL, Valeriano. Historia de las ideas estéticas y de las teorias artísticas contemporáneas. Vol. I. Madrid: Visor.

KANT, Immanuel (2001). Crítica del juicio. Madrid: Austral.

- (2003). Crítica de la razón pura. Madrid: Clásicos Alfaguara.

LAMBERT, Jean-Clarence (1969). Pintura abstracta. Madrid: Aguilar.

LIPOVETSKY, Gilles (1990). El imperio de lo efimero. La moda y su destino en las sociedades modernas. Barcelona: Anagrama.

LONGAIR, Malcolm S. (1998). La evolución de nuestro universo. Madrid: Cambridge University Press.

LORENTE, Jesús-Pedro (2002). «Amados cadáveres. Poética de la contemplación intimista en el arte romántico». Catálogo de la exposición Amor y Muerte en el Romanticismo. Barcelona: Fondos del Museo Romántico, Ministerio de Educación, Cultura y Deporte-CAM.

LUHMANN, Niklas (1997). Observaciones de la modernidad. Racionalidad y contingencia en la sociedad moderna. Barcelona: Paidós.

- (2000). La realidad de los medios de masas. Barcelona: Universidad Iberoamericana-Anthropos.

LYON, David (1997). Posmodernidad. Madrid: Alianza.

LYOTARD, François (1984). La condición postmoderna. Madrid: Cátedra.

- (1985). La postmodernidad (explicada a los niños). Barcelona: GEDISA.

MANnHeIM, Karl (1962). Ensayos de sociología de la cultura. Madrid: Aguilar.

- (1966). Ideología y utopía: introducción a la sociología del conocimiento. Madrid: Aguilar.

- (1990). El problema de una sociología del saber. Madrid: Tecnos.

MONTESQuieu (1997). Cartas persas. Madrid: Cátedra.

MARX, Carlos (1998). Manifiesto Comunista. Barcelona: Crítica.

MORNET, Daniel (1988). El pensamiento francés en el siglo XVIII. El trasfondo intelectual de la Revolución Francesa. Madrid: Ediciones Encuentro.

Mosse, George L. (1997). La cultura europea del siglo XIX. Barcelona: Ariel.

- (1997). La cultura europea del siglo XX. Barcelona: Ariel.

MosZYNSKA, Anna (1999). El arte abstracto. Barcelona: Ediciones Destino-Thames and Hudson.

MuncK, Thomas (2001). Historia social de la Ilustración. Barcelona: Crítica.

Novalis (2004). Himnos a la noche. Enrique de Ofterdinger. Madrid: Cátedra.

Oltra, Benjamín; Garrigós, José Ignacio; ManteCón, Alenjandro; Oltra Algado, Christian (2004). Sociedad, vida y teoría. La teoría sociológica desde una perspectiva de sociología narrativa. Madrid: CIS.

Pagden, Anthony (2001). La Ilustración y sus enemigos. Dos ensayos sobre los orígenes de la modernidad. Barcelona: Península.

Pérez Carreño, Francisca (1996). "La estética empirista». En Bozal, Valeriano. Historia de las ideas estéticas y de las teorias artísticas contemporáneas. Vol. I. Madrid: Visor.

PICÓ, Josep (1988). «Introducción». Modernidad y Posmodernidad. Madrid: Alianza. RAQUEJO, Tonia (1996). «El Romanticismo británico». En BOZAL, Valeriano. Historia de las ideas estéticas y de las teorías artísticas contemporáneas. Vol. I. Madrid: Visor.

RifKIN, J. (2000). La era del acceso. La revolución de la nueva economía. Barcelona: Paidós.

RiTZER, George (2001a). Teoría sociológica clásica. Madrid: McGraw Hill.

- (2001b). Teoría sociológica moderna. Madrid: McGraw Hill. 
Roche Cárcel, Juan A. (2004). «El capitalismo evanescente». Reflexiones Sociológicas. Homenaje al Profesor José Castillo Castillo. Reflexiones sociológicas. Madrid: CIS.

- (en prensa). «De la paradoja a la simplificación o comprender la cultura contemporánea». En RoDríGUEZ MORATÓ, Arturo; GINER, Salvador (eds.). La sociedad de la cultura, un nuevo lugar para las artes en el siglo XXI. Barcelona: CIS-Universitat de Barcelona.

ROUSSEAU, Jean-Jacques (2003). Del contrato social. Sobre las ciencias y las artes. Sobre el origen y los fundamentos de la desigualdad entre los hombres. Madrid: Alianza.

RusSELL, Bertrand (1984). ABC de la relatividad. Barcelona: Ariel.

SÁNCHEZ CAPDEQUí, Celso (2004). Las máscaras del dinero. El simbolismo social de la riqueza. Barcelona: Anthropos - Universidad Autónoma Metropolitana.

SÁNCHEZ Ron, José Manuel (2000). El siglo de la ciencia. Madrid: Taurus.

SCHILlER, Kallias (1999). Cartas sobre la educación estética del hombre. Barcelona: Anthropos.

SCHMiDT, Alfred (1968). El concepto de naturaleza en Marx. México: FCE.

SCHÜTZ, Alfred (1993). La construcción significativa del mundo social. Introducción a la sociología comprensiva. Barcelona: Paidós.

SHATTUCK, R. (1991). La época de los banquetes. Orígenes de la vanguardia en Francia: de 1885 a la Primera Guerra Mundial. Madrid: Visor.

SEARLE, John R. (1997). La construcción de la realidad social. Barcelona: Paidós.

Simmel, Georg (1977). Filosofía del dinero. Madrid: Instituto de Estudios Políticos.

- (1986). El individuo y la libertad. Barcelona: Península.

SOlANA, Guillermo (1996). «El Romanticismo francés. El monólogo absoluto». En BOZAL, Valeriano. Historia de las ideas estéticas y de las teorías artísticas contemporáneas. Vol. I. Madrid: Visor.

Solomon, Robert C.; Higgins, Kathleen M. (1999). Breve historia de la filosofía. Madrid: Alianza.

STAROBINSKI, Jean (1988). 1789. Los emblemas de la razón. Madrid: Taurus.

Strahler, Arthur N.; STRAHLER, Alan H. (1994). Geografia fisica. Barcelona: Editorial Omega.

SUBIRATS, Eduardo (1989). El final de las vanguardias. Barcelona: Anthropos.

TATARKIEWICZ, Wladyslaw (1992). Historia de seis ideas. Arte, belleza, forma, creatividad, mimesis, experiencia estética. Madrid: Tecnos.

TerCeIro, José B. (1996). Sociedad digital. Del homo sapiens al homo digitalis. Madrid: Alianza.

Thiebaut, Carlos (1996). «La mal llamada postmodernidad (o las contradanzas de lo moderno)». En BOZAL, Valeriano. Historia de las ideas estéticas y de las teorias artísticas contemporáneas. Vol. II. Madrid: Visor.

TollinCHI, Esteban (1989). Romanticismo y Modernidad. Ideas fundamentales de la cultura del siglo XIX. Vol. I y II. Editorial de la Universidad de Puerto Rico.

TORTOSA Blasco, José María (1981). Estructura y proceso. Estudios de Sociología de la Cultura. Alicante: C.A.A.M.

Uña JuÁrez, Octavio; Hernández SÁnCheZ, Alfredo (dirs.) (2004). Diccionario de sociología. Madrid: ESIC - Universidad Rey Juan Carlos.

VATtimo, Gianni, El fin de la modernidad. Nihilismo y hermeneútica en la cultura posmoderna, GEDISA Barcelona, 1995.

VAUGHAN, William (1995). Romanticismo y Arte. Barcelona: Ediciones Destino-Thames and Hudson.

Voltaire (1988). Cartas filosóficas. Madrid: Alianza. 
Watson, Peter (2002). Historia intelectual del siglo XX. Barcelona: Crítica.

Weber, Max (1974). Sobre la teoría de las Ciencias Sociales. Barcelona: Península. - (1990). Ensayos sobre metodología sociológica. Buenos Aires: Amorrortu.

Wellmer, Albrecht (1988). «La dialéctica de la Modernidad y Postmodernidad». En PICÓ, Josep (ed.). Modernidad y Posmodernidad. Madrid: Alianza.

WoOlleY, Benjamin (1994). El universo virtual. Madrid: Acento editorial. 